\title{
Spatial overlap between sympatric wild and domestic herbivores links to resource gradients
}

\author{
Fadzai M. Zengeya ${ }^{\mathrm{a}, *}$, Amon Murwira ${ }^{\mathrm{a}}$, Alexandre Caron ${ }^{\mathrm{b}, \mathrm{d}}$, Daniel Cornélis ${ }^{\mathrm{b}}$, \\ Patience Gandiwa ${ }^{\mathrm{e}}$, Michel de Garine-Wichatitsky ${ }^{\mathrm{b}, \mathrm{c}}$ \\ a Department of Geography and Environmental Science, University of Zimbabwe, PO Box MP167, Mount Pleasant, Harare, Zimbabwe \\ ${ }^{\mathrm{b}}$ International Research Center in Agriculture for Development-UPR AGIRs, Department Environment and Society, TA C 22/E Campus \\ International de Baillarguet, Cedex 5, 34398 Montpellier, France \\ ${ }^{\mathrm{c}}$ Research Platform Production and Conservation in Partnership, Department of Biological Sciences, University of Zimbabwe, MP167, \\ Mount Pleasant, Harare, Zimbabwe \\ ${ }^{\mathrm{d}}$ International Research Center in Agriculture for Development (CIRAD) Harare, P.O Box 1378, Harare, Zimbabwe \\ e Zimbabwe Parks and Wildlife Management Authority, P.O Box CY 140, Causeway, Harare
}

\section{A R T I C L E I N F O}

\section{Article history:}

Received 29 July 2015

Received in revised form

5 November 2015

Accepted 5 November 2015

\section{Keywords:}

Wildlife-livestock interface

Neighborhood density function

GPS

Habitat overlap

African buffalo

\begin{abstract}
A B S T R A C T
In this study, we investigated the relationship between resource gradients and overlap between wild and domestic herbivores in a southern African ecosystem. We used an Enhanced Vegetation Index (EVI) to identify and test the presence of resource gradients i.e. vegetation greenness between agricultural areas and conservation areas in Southeastern Zimbabwe, part of the Great Limpopo Transfrontier Conservation Area. We then tested whether these resource gradients coincide with GPS collared cattle (Bos taurus) movements into wildlife areas, as well as drive spatial overlaps between cattle and the GPS collared African buffalo (Syncerus caffer). Results showed that resource gradients although variable, exist between the conservation area and surrounding agricultural area. Cattle used the conservation area less than expected during the dry season when vegetation greenness in the communal land was relatively lower than in the conservation area. Significant spatial segregation between cattle and buffalo occurred during the wet season and late dry season, while spatial aggregation occurred during the early dry season. Intensity of habitat overlap between cattle and buffalo during the early dry season was relatively high in habitats preferred by both species. Our results suggest that cattle movement into conservation areas is linked to resource gradients.
\end{abstract}

(c) 2015 Elsevier B.V. All rights reserved.

\section{Introduction}

Increasing human and livestock populations adjacent to conservation areas have led to an intensification of wildlifelivestock interactions resulting in competition over resources and conflicts associated with predation, crop destruction, and disease transmission (de Garine-Wichatitksy et al.,

\footnotetext{
*Corresponding author. Tel.: +263 4303211; fax: +263 4303286/ $+2634307119$

E-mail address: fmz@classicmail.co.za (F.M. Zengeya).
}

2013). Minimizing contacts between wildlife and livestock in order to reduce these risks remains a key challenge for biodiversity conservation, livestock production and the health of socio-ecological systems (Lamarque et al., 2009). Identifying key factors influencing interactions between livestock and wildlife is therefore critical for land use planning and other management tools where livestock production co-exists with wildlife conservation.

Several factors that include biophysical, social and human activities (Redfern et al., 2003; Hebblewhite and Merrill, 2008; Winnie et al., 2008) have been linked to animal movements. However, food availability has remained a key 
driver of herbivore movements as it is closely linked to their survival and reproduction (McLoughlin and Ferguson, 2000; Berger, 2004). For instance, the large scale migration patterns of animals in the Serengeti-Mara ecosystem has been hypothesized to correlate with rainfall patterns that lead to new green forage (Jarman and Sinclair, 1979; Boone et al., 2006). Similarly at local scales related processes could occur as variations in forage availability in space and time lead to resource gradients that are likely to influence animal movement. We therefore hypothesize that resource gradients that are linked to changes in forage availability drive movement and overlaps between livestock and wildlife at interfaces between agricultural and wildlife areas. This is based on the premise that increased human and livestock populations result in the emergence and intensification of resource gradients between agricultural and conservation areas. Despite being important, the nature of resource gradients and their effect on livestock movement remains underexplored.

Resource driven movements often result in interaction between species. Under resource-limited conditions, it is hypothesized that sympatric species of similar body size and diet are likely to compete (Vavra et al., 1999; Augustine et al., 2011). Animals are therefore expected to respond to resource competition by altering habitat use or diet (Loft et al., 1991; Fritz et al., 1996). Such changes in foraging behavior likely lead to spatial partitioning, especially when both livestock and wildlife species are involved (Sinclair, 1985; Hibert et al., 2010). However, few studies have considered spatial partitioning or quantified spatial habitat overlap in a spatially explicit manner for sympatric wild and domestic herbivores. Furthermore, these studies have often relied on aerial survey data or field observations which, although useful, often cover a short period to enable detection of potential competition. Thus, methods that can allow detection or quantification of spatial interaction in a spatially explicit manner over a longer period become important. In this regard, the use of Global Positioning Systems (GPS) could allow detection of the overlap patterns between livestock and wildlife at this scale and further provide opportunities of evaluating the influence of resource gradients.

In this study, we investigated whether resource gradients linked to changes in forage availability exist between agricultural and wildlife conservation areas. We tested whether cattle (Bos taurus) movement into wildlife areas was linked to resource gradients, as well as agricultural fields. We also investigated the spatial response of the African buffalo (Syncerus caffer) to the presence of semi-free range cattle inside the conservation area, as well as, quantifying variations in habitat overlaps. Our hypotheses were: (1) cattle movements into the conservation area are driven by resource gradients, (2) the cropping cycle influences cattle movement into the conservation area, and (3) cattle movement into the conservation area results in spatial segregation with the African buffalo during resource limited periods.

\section{Methods and materials}

\subsection{Study area}

The study was conducted at a wildlife-livestock interface in the Southeast Lowveld of Zimbabwe within the Great Limpopo Transfrontier Conservation Area (GLTFCA) between August 2008 and November 2009. The area consists of two land use types, an agricultural area, (Malipati communal land) and a conservation area consisting of Gonarezhou National park (GNP) and Malipati Safari area hereinafter referred to as the conservation area (Fig. 1). The area is semi-arid with a mean annual rainfall of $300-600 \mathrm{~mm}$. Most of the rainfall received annually occurs between November and April. Mean annual temperature ranges from $25^{\circ} \mathrm{C}$ to $27^{\circ} \mathrm{C}$ (Chenje et al., 1998) with a mean maximum temperature of $33^{\circ} \mathrm{C}$ in October and a mean minimum temperature of $13.3^{\circ} \mathrm{C}$ in June based on the records of the Meteorological Services Department, Zimbabwe. Altitude varies from $300 \mathrm{~m}$ to $600 \mathrm{~m}$ above mean sea level (Chenje et al., 1998). Soils in the study area are predominantly basalt-derived vertisols (Nyamudeza et al., 2001). The vegetation of the study area is mainly composed of Mopane-dominated woodland (Colophospermum mopane). Other dominant vegetation types in the study area include Combretum-dominated woodland, Acacia-dominated shrubland and riparian woodland. Open grasslands also occupy a smaller area while agricultural fields extensively span across the study area creating a heterogeneous landscape. Mwenezi River which runs through the study area supports both wildlife and livestock.

Within the communal land, land use activities include livestock production and cropping (Nyamudeza et al., 2001). Livestock particularly cattle have been observed to use the adjacent conservation area for illegal grazing with an average of 167 cattle being observed at peak times (Murwira et al., 2013).

The conservation area contains a diverse range of wildlife species such as the African elephant (Loxodonta africana), giraffe (Giraffa camelopardalis), buffalo (Syncerus caffer) and some rare species in Zimbabwe such as the wild painted dog (Lycaon pictus), bat eared fox (Octocyon megalotis), roan antelope (Hippotragus equines) and nyala (Tragelaphus angasii) (Dunham et al., 2010).

\subsection{Cattle and buffalo data}

In order to understand fine scale movements of cattle and overlaps with buffalo herds, we used GPS collars (African Wildlife Tracking collars, Pretoria, South Africa) fitted on randomly selected cattle and buffalo herds. We selected twelve cattle herds (with farmers joining the protocol on a voluntary basis) in the communal land and four buffalo herds in the southern region of GNP (based on groups located by helicopter). One adult lead cow was selected to represent each cattle herd and fitted with a GPS collar. Buffalo were immobilized using established techniques by helicopter (Burroughs et al., 2006; Lagrange, 2006). A total of three GPS collars were fitted per selected buffalo group in order to enhance chances of detecting potential overlaps with cattle since buffalo herds are known to be subject to fission and fusion (Prins, 1996). The 


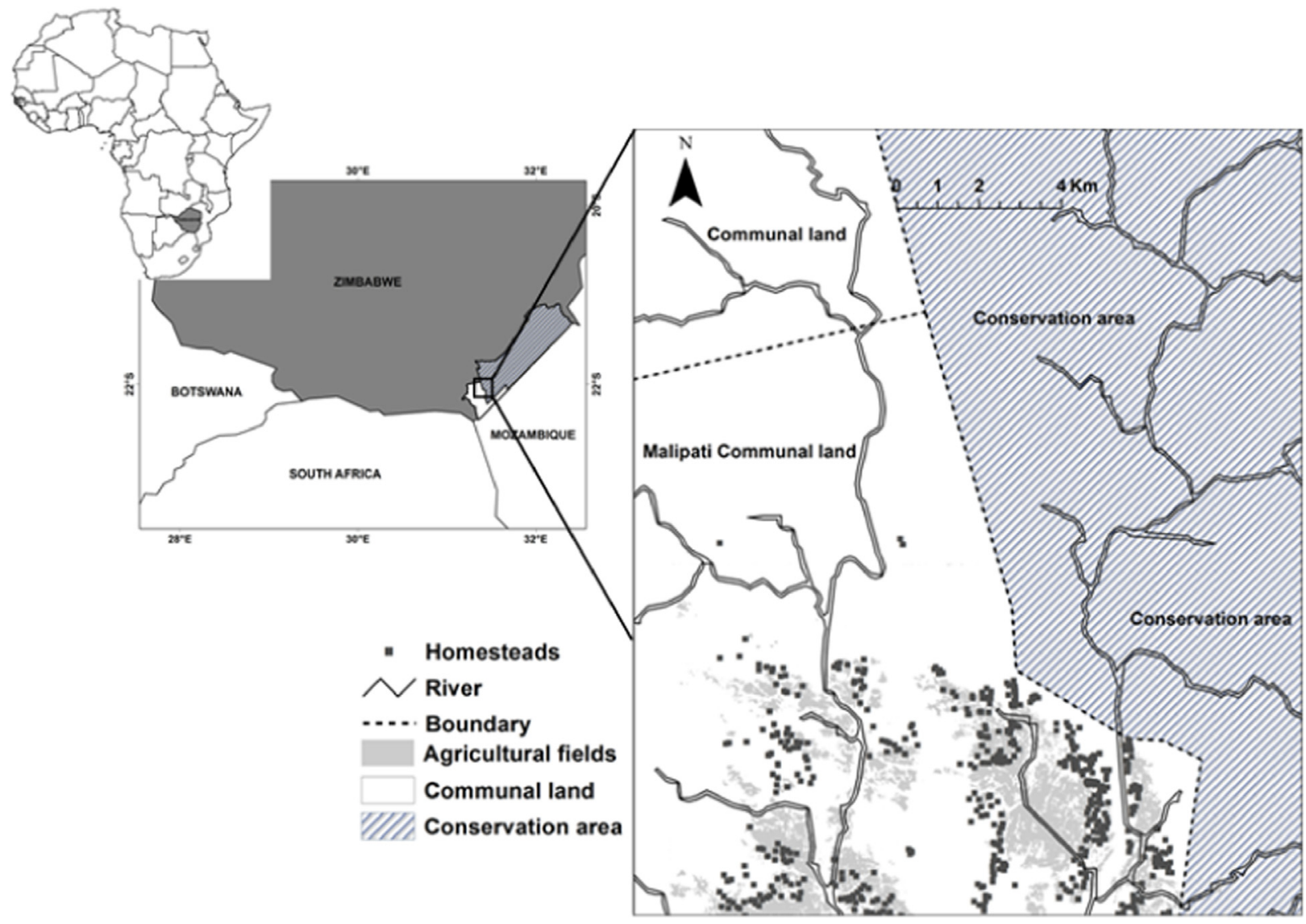

Fig. 1. Location of the study area in the Southeast lowveld of Zimbabwe.

GPS collars were programmed to log the cattle and buffalo positions in geographic coordinates based on the WGS84 spheroid at hourly intervals from August 2008 to July 2009 and October 2008 to November 2009 respectively. The geographic coordinates were then re-projected to Universal Transverse Mercator (UTM) zone 36 south based on WGS 84 spheroid. However, due to GPS collar malfunction, the cattle sample size was reduced to nine (for the period September 2008 to July 2009) and ten individuals for buffalo.

Cattle herds studied were semi-free range, normally driven to the grazing area during the day and left to graze with minimal human interference and then driven back to the kraal for safe keeping overnight. We discounted GPS readings within the kraal at a $15 \mathrm{~m}$ radius (relative error of the GPS collars) from the center of the kraal in ArcGIS GIS 9.2 (ESRI, 2005) to avoid bias, as these did not reflect the animal's foraging patterns.

\subsection{Analysis of the resource gradient}

We used MOD13Q1 MODIS 16 day (250-m) Enhanced Vegetation Index (EVI) data for the period September 2008July 2009 as a measure of vegetation greenness and therefore forage availability. EVI data was downloaded from the USGS EROS Data Center (http://lpdaac.usgs.gov/) and reprojected from sinusoidal projection to UTM zone 36 south based on WGS 84 Spheroid in ENVI 4.7 (ITT Visual Information Solutions, 2009). EVI has been shown to be effective in monitoring the Earth's terrestrial photosynthetic vegetation activity (Xiao et al., 2004; Huete et al., 2010) thus providing a useful measure of vegetation greenness. Vegetation greenness often correlates well with the nutritional quality of vegetation and biomass (Huete et al., 2002; Macandza et al., 2004). Consequently, studies on herbivore distribution have used EVI as a proxy for vegetation greenness or quantity (Loarie et al., 2009; Naidoo et al., 2012). Post-processing of the EVI data involved applying a Fourier Transform to remove residual effects/noise, resulting from interference of e.g. clouds (Roerink et al., 2000). Next, we calculated the average EVI for each of the months in a GIS.

In order to determine whether a resource (EVI) gradient existed from the communal land to the conservation area, we created buffer distances on both sides of the conservation area boundary. The buffer in the conservation area was based on the observed maximum distance traveled by GPS collared cattle into the conservation area $(\sim 2500 \mathrm{~m})$, while outside the conservation area it was based on the maximum distance that the cattle traveled away from the conservation area boundary $(\sim 5000 \mathrm{~m})$. We then constructed conservative buffers of $6000 \mathrm{~m}$ and $3000 \mathrm{~m}$ outside and inside the conservation area respectively. Next, we randomly selected transects ( $n=30$ based on exploratory data analysis) that traversed the conservation area boundary 
from the edge of the communal land buffer to the edge of the conservation area buffer. We then extracted EVI along these transects using overlay analysis. All spatial data processing were conducted in ArcGIS GIS 9.2 (ESRI, 2005). A Mann Kendall test was used to test for the existence, nature and significance of resource gradients.

\subsection{Linking cattle distribution with agricultural fields}

We assessed whether the spatial distribution of cattle was influenced by the distribution of agricultural fields based on the notion that the cropping cycle would affect use of agricultural fields by cattle. To achieve this, we used an agricultural field layer derived from classified IKONOS imagery $(\kappa=0.86)$ using ENVI 4.7 (ITT Visual Information Solutions, 2009). We then calculated distance from the agricultural field edges using the distance function in ILWIS GIS (ITC, 2005). Next, we used overlay analysis to relate each GPS location with the distance from the agricultural fields. We used cattle data for June to represent the dry season whilst March represented the wet season. June was selected based on the knowledge that most of the cattle in the study area are allowed into the fields during this month unlike March which is at the peak of the cropping season when field guarding is intensive. We evaluated the degree to which cattle were attracted or repelled from the fields by plotting maps and histograms and then calculating measures of skewness for both wet and dry seasons. We also calculated median distances from the agricultural fields for both months after data were found to deviate from a normal distribution using Kolmogorov-Smirnov test $(p<0.05)$ in SPSSC.

\subsection{Quantifying cattle and buffalo space use}

We calculated monthly home ranges for cattle and buffalo separately using the fixed kernel method (Worton, 1989) in ArcGIS GIS 9.2 (ESRI, 2005). Selection of the smoothing factor was based on Zengeya et al. (2011) while the home range was based on the $90 \%$ probability contour following Börger et al. (2006). The kernel method produces a utilization distribution (UD) based home range. The UD defines the probability distribution of an animal's space use by describing the relative amount of time that an animal spends in any place (Seaman and Powell, 1996). The UD provides a useful measure of overlap as it is able to quantify the intensity of overlap between two individuals.

\subsection{Conservation area use by cattle}

We calculated the proportion of the home range observed inside and outside the conservation area from September 2008-July 2009 for seven out of the nine herds that made variable use of the conservation area. Only seven cattle herds were observed to use the park during the study period. We tested whether the proportion of the home range inside and outside the conservation area significantly differed using a paired $t$-test after data were found to be normally distributed $(p>0.05$, Shapiro Wilk test). This allowed detection of periods that cattle relatively spent more time in the conservation area than expected. Statistical analyses were performed using SPSSC .

Next, we determined whether there was an observable relationship between the proportion of the home range in the conservation area and the slope coefficient from the trend analysis of EVI. We expected the proportion of the home range to be larger in the conservation area when the gradient was positive, that is, higher EVI in the conservation area than in the communal land. In order to achieve this we used a LOESS smoother in Splus ${ }^{\circledR}$ to determine the nature of the relationship between the EVIslope and the mean proportion of the HR in the conservation area. A Loess smoother uses a smoothing function that allows the underlying relationship between the predictor (EVIslope) and response (proportion of HR in the conservation area) variable to be estimated using local polynomials to fit the data (Floyd et al., 2009).

\subsection{Cattle-buffalo spatial association}

We used the bivariate Neighborhood Density Function (NDF) (Condit et al., 2000) to assess whether cattle used areas close to buffalo i.e. whether cattle and buffalo were spatially segregated, aggregated or random during the period October 2008-July2009. The NDF $\left(\Omega_{x}\right)$ is the relative mean density (observed density/event set density) at distance $d_{i}$ from all points. The NDF is similar to Ripley's $K$ function. However, the NDF has the added advantage of not being cumulative, allowing inferences to be made at specific distances (Condit et al., 2000; Perry et al., 2006). The NDF has been used for understanding plant spatial patterns, but has rarely been implemented on distribution patterns of herbivores. The NDF is formulated as $\Omega_{x}=D_{x} / \lambda$ where $\lambda$ is the mean density of a given species. $D_{x}=\sum N_{x} /$ $\sum A_{x}$, where $A_{x}$ is the area in each annulus at distance $x, N_{x}$ is the number of neighbors within the annulus. For bivariate patterns (i.e. composed of species 1-cattle and species 2-buffalo),the NDF is the number of events of species 2 between $x$ and $x+\Delta x$ meters for all $x+\Delta x$ within the plot of events of species 1 .

We used Monte Carlo simulation to generate $99 \%$ confidence intervals under the hypothesis of spatial independence. Based on this hypothesis, the locations of type 2 events (buffalo) should be random with respect to those of type 1 events (cattle) (Bailey and Gatrell, 1995). Departure from independence indicates that the two patterns show either aggregation or segregation. Thus, when there are more neighbors of type 2 within a distance $x$ of an arbitrary type 1 event than expected under the assumption of independence, $\Omega_{x}$ is $>1$ indicating an attraction between the two populations. When $\Omega_{x}<1$ it indicates repulsion between the two types of events and when $\Omega_{x}=1$, the patterns are random. This approach also allowed the identification of months that cattle and buffalo likely overlap in space.

\subsection{Habitat overlaps between cattle and buffalo}

Based on the spatial association analysis, we identified the months when significant spatial aggregation occurred. Using these months, we calculated the intensity of 
spatial overlap within habitats (excluding water) contained in the area of overlap between cattle and buffalo home ranges using the utilization distribution overlap index (UDOI) (Fieberg and Kochanny, 2005). UDOI performs better than most overlap indices at accounting for the degree of joint space use as it takes the product of the two animal UDs (Fieberg and Kochanny, 2005). Overlap values range between 0 and 1 with 1 indicating complete overlap while 0 indicating no overlap. However, UDOI values can be $>1$ when the two UDs are non-uniformly distributed and have a high degree of overlap. Habitat types were derived from a landcover map classified from an IKONOS (4 m) satellite image of April 2008 accuracy of $88 \%(\kappa=0.86)$ (Zengeya et al., 2014). The classes included Mopane woodland, Acacia shrub, Combretum woodland, riparian forest, bare areas, water, open grassland and agricultural fields. In this study we only considered spatial or habitat overlap and not diet overlap as it required extensive field measurements.

\section{Results}

\subsection{Temporal changes in resource distribution}

We observed a significant but weak resource (EVI) gradient from the communal land to the conservation area throughout the study period (Fig. 2). From September to
November there was a significant positive EVI gradient from the communal land to the conservation area (Mann Kendall's $\tau=0.206-0.223$ ) whilst a significant negative EVI gradient existed in the same direction between December-February (Mann Kendall's $\tau=-0.059$ to -0.213 ). We also observed a significant positive EVI gradient from March-July (Mann Kendall's $\tau=0.130-0.229$ ).

\subsection{Influence of agricultural fields on cattle distribution}

During the wet season cattle used areas away from agricultural fields whereas in the dry season cattle concentrated in agricultural areas (Fig. 3(a-b)). The distribution of cattle was positively and strongly skewed $(2.676 \pm 0.062(\mathrm{SE}))$ towards agricultural fields during the dry season i.e. June, whilst in the wet season the distribution of cattle was relatively skewed away $(1.397 \pm 0.069)$ from agricultural fields (Fig. 3(c)). Median distance from agricultural fields during the dry season (June) was $10 \mathrm{~m}$ and $405 \mathrm{~m}$ during the wet season (March).

\subsection{Cattle incursion into the conservation area}

The proportion of cattle home range observed within the conservation area significantly varied during the study period (Fig. 4). The proportion of home range area in the conservation area steadily increased from the late dry season - October through the early wet season - November
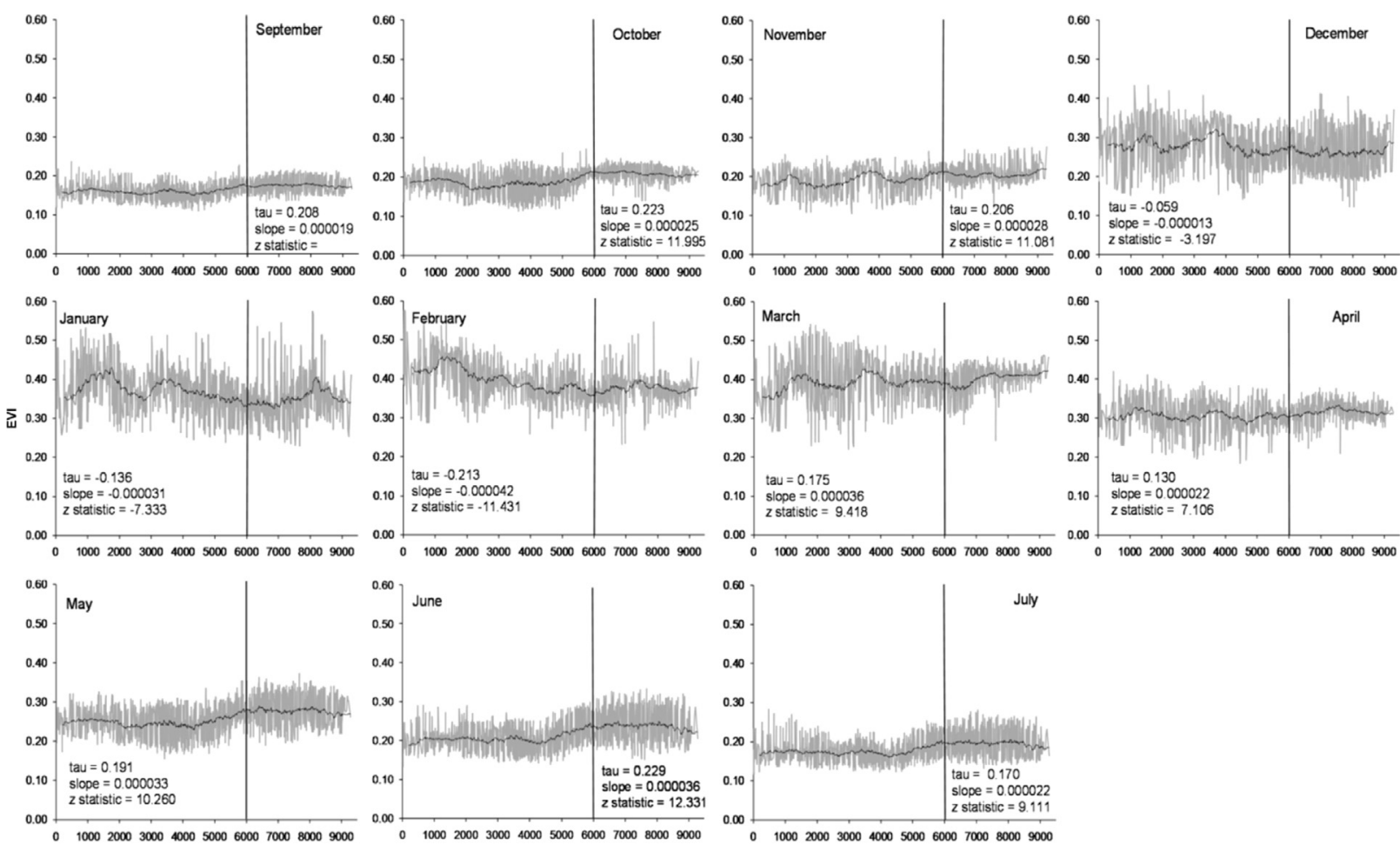

Distance to communal land (m)

Fig. 2. Resource gradients (EVI) from the communal land and conservation area for the period September 2008-July 2009. Trend analysis is based on Mann-Kendall trend test and significance is based on the $z$ statistic at $95 \%$ level. The distance band $0-6000 \mathrm{~m}$ represents the communal land whilst the 6000-9000 $\mathrm{m}$ represents the conservation area. The dividing line at $6000 \mathrm{~m}$ represents the conservation boundary. 

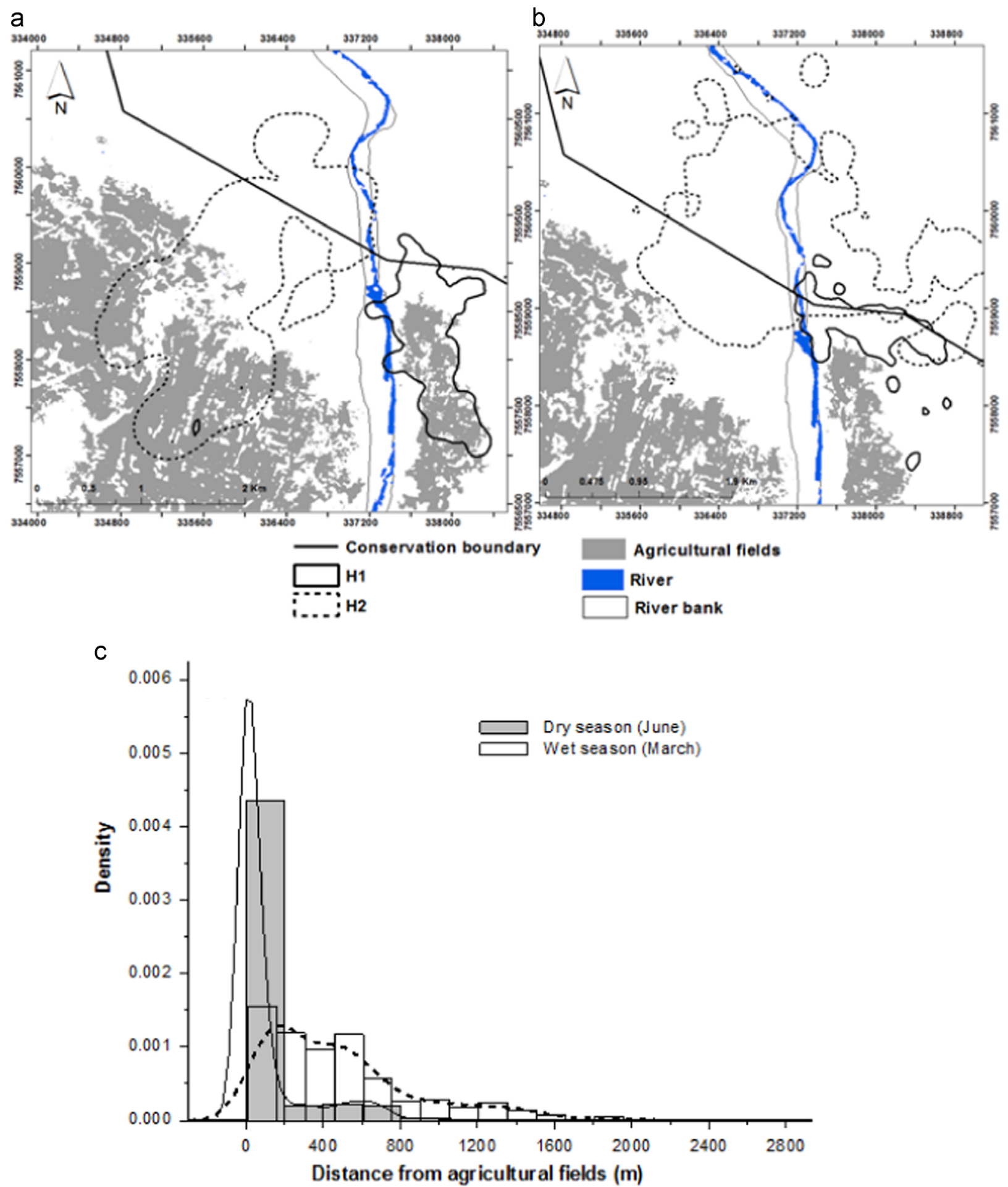

Fig. 3. Cattle home ranges in relation to agricultural field distribution in the (a) dry (b) wet season for Herd 1 (H1) and Herd 2 (H2) and (c) histograms of cattle GPS location relative to distances from agricultural fields during the dry and wet season.

The proportion of cattle home range area in the conservation area peaked in December but declined from January to July. A relatively smaller proportion of the home range area was noted in the conservation area in the early dry season June-July. The proportion of the home range inside and outside the conservation area was not significantly different during the months of November $(t=-0.901, \mathrm{~d} f=6$, $P=0.402)$, December $(t=-0.606, \mathrm{~d} f=6, P=0.567)$, January $(t=-2.289, \mathrm{~d} f=5, P=0.07)$ and February $(t=-1.963, \mathrm{~d} f=7$, $P=0.09$ ). 


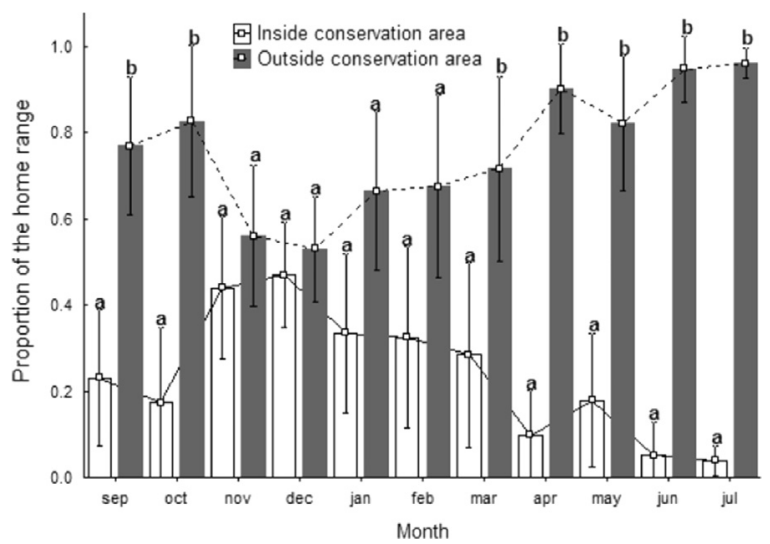

Fig. 4. Proportions of cattle home ranges found within and outside the conservation area for the period September -July. Bars with different letters indicate significant differences.

A bimodal relationship was observed between the mean proportion of HR and EVIslope (Fig. 5). The proportion of HR in the conservation was relatively higher when the EVIslope was negative i.e. higher resources in the communal land and lower resources in the conservation area. The proportion of HR in the conservation area was relatively lower when the EVIslope was positive-higher resources in the conservation area. We observed a steady increase in the proportion of the HR when EVIslope was positive and then steadily declined forming a hump shape.

\subsection{Buffalo and cattle spatial association}

Spatial association between buffalo and cattle in October was random at distances up to $500 \mathrm{~m}$ and became segregated at distances greater than $500 \mathrm{~m}$ (Fig. 6). Significantly strong spatial aggregation occurred in May at distances of $100 \mathrm{~m}$ to $2800 \mathrm{~m}$ above which it became random and then significantly segregated at $3200 \mathrm{~m}$. There was significant spatial aggregation in June which occurred at $300 \mathrm{~m}$ and between $500 \mathrm{~m}$ and $2700 \mathrm{~m}$. Spatial aggregation occurred in July from $400 \mathrm{~m}$ to $2300 \mathrm{~m}$ after which it became random. Significant spatial segregation at all distances occurred in December and January while in February-April segregation occurred at relatively short distances while aggregation occurred at larger distances.

\subsection{Intensity of home range overlaps in relation to habitats}

Based on the spatial association analysis, buffalo and cattle spatially aggregated in May, June and July. Mean intensity of spatial overlap was relatively high within Combretum woodland, Mopane woodland and bare areas in May, while in June a higher overlap occurred within Mopane woodland (Table 1). In July overlap mainly occurred in Combretum woodland and riparian forest. Intensity of overlap values were relatively high in May compared with June and July.

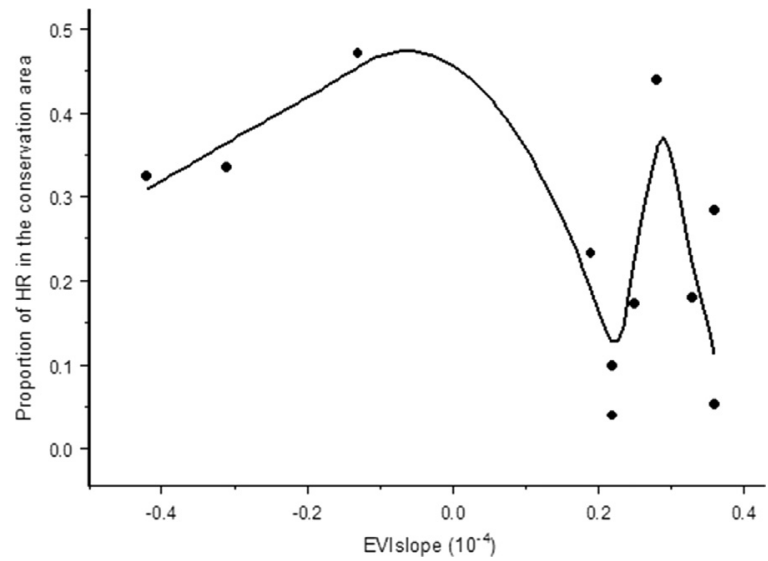

Fig. 5. Influence of resource gradients (EVI slope coefficient) on proportion of HR in the conservation. The solid line is a loess smooth curve fit (Residual error $=0.124$ ).

\section{Table 1}

Mean intensity of overlap (UDOI) \pm standard error between cattle and buffalo within different habitats during the dry season months. $N=$ number of cattle-buffalo pairs included in the calculation.

\begin{tabular}{|c|c|c|c|}
\hline Habitat & May $(n=6)$ & June $(n=8)$ & July $(n=8)$ \\
\hline $\begin{array}{r}\text { Combretum } \\
\text { woodland }\end{array}$ & $1.319(0.405)$ & $0.030(0.007)$ & $0.088(0.035)$ \\
\hline $\begin{array}{l}\text { Acacia } \\
\text { shrubland }\end{array}$ & $0.092(0.033)$ & $0.009(0.005)$ & $0.002(0.002)$ \\
\hline $\begin{array}{l}\text { Open } \\
\text { grassland }\end{array}$ & $0.018(0.004)$ & $0.0004(0.0001)$ & $0.00008(0.00003)$ \\
\hline $\begin{array}{l}\text { Mopane } \\
\text { woodland }\end{array}$ & $0.319(0.105)$ & $0.479(0.233)$ & $0.035(0.012)$ \\
\hline $\begin{array}{l}\text { Riparian } \\
\text { woodland }\end{array}$ & $0.035(0.012)$ & $0.027(0.012)$ & $0.068(0.029)$ \\
\hline Bare area & $0.378(0.120)$ & $0.024(0.012)$ & $0.001(0.0005)$ \\
\hline
\end{tabular}

\section{Discussion}

Cattle made variable use of the conservation area and this was correlated with the EVI gradient. Although the strength of the detected EVI gradients was generally weak, it was significant indicating existence of a resource gradient between the agricultural and conservation areas. Cattle made more use of the conservation area in the wet season (November-March) compared to the dry season contrary to expectation. A possible reason for the use of the conservation area at this time could be the cropping activities which start from November (field preparation) to March (mature crops). As a result, cropped land is made inaccessible to cattle resulting in the compression of the rangeland. Thus, the resource rich zone of the crop fields especially from January to March (when crops are at peak growth to maturity) is not available for livestock (Fig. 3(b)). When vegetation greenness declined outside the conservation area in the early dry season (June-July), cattle used the conservation area less than expected. This could be a result of cattle having access to agricultural fields that offer crop residues following harvest (Fig. 3(a)). Early dry season crop residues offer nutritious supplement for cattle in an otherwise forage limited landscape (Bennett et al., 2007). Overall, we assert that resource gradients and the 

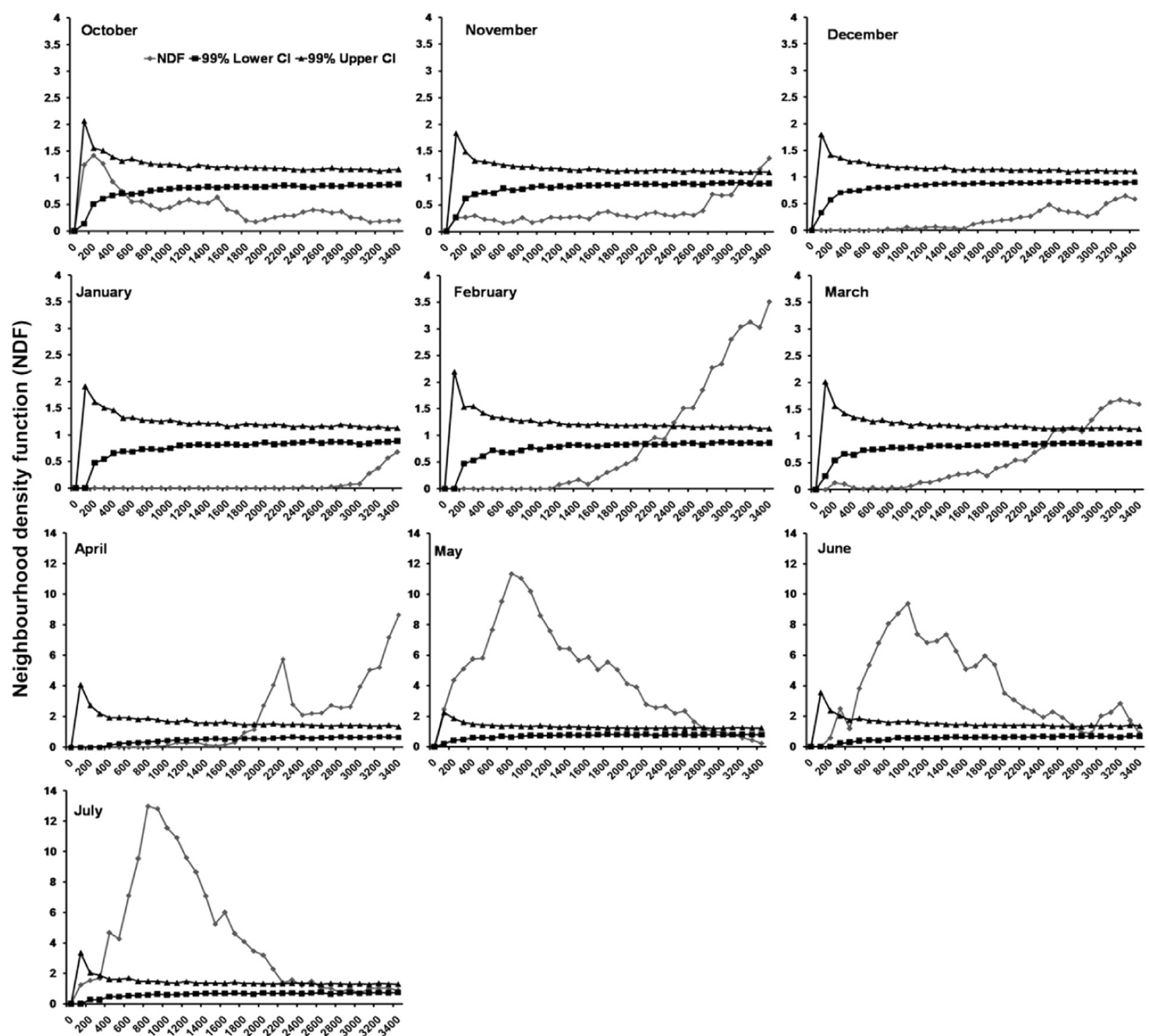

\section{Distance $(m)$}

Fig. 6. Spatial associations between buffalo and cattle during October 2008-July 2009 using the Neighborhood density function (NDF). Confidence intervals are at the $99 \%$ and based on 499 randomizations. Values above the confidence interval indicate aggregation between cattle and buffalo, while lower values indicate segregation.

cropping cycle are among the underlying factors influencing cattle use of the landscape.

Significant spatial aggregation was observed between cattle and buffalo during the early dry season whilst segregation was observed during the late dry season and early wet season to late wet season. The early dry season results are consistent with Voeten and Prins (1999) who reported similar findings between cattle and wildebeest (Connochaetes Taurinus). In semi-arid areas, the early dry season is characterized by limited amounts of high quality food (Zengeya et al., 2013) available to both livestock and wildlife as senescent grass. This could influence potential competition between livestock and wildlife. In fact, sympatric species of similar body weight and diet such as cattle and buffalo are expected to compete especially when shared resources are limited (Prins and Olff, 1998; Odadi et al., 2011) making competition unlikely during the wet season. However, the early dry season results contradict studies that suggest segregation as indicative of competition (Loft et al., 1991; Stewart et al., 2002; Madhusudan, 2004; Hibert et al., 2010). On the other hand, segregation occurred during the early wet season (November) when resources are limited in quantity (Voeten and Prins, 1999) facilitating possible competition. A similar pattern occurred for the late dry season (October) when cattle and buffalo were independent of each other at smaller distances and became segregated at larger distances. Hibert et al. (2010) reported a similar pattern between cattle and buffalo during the dry season using aerial survey data. Overall, results suggest that both segregation and aggregation occurred when resources were 
limited in our study area. We can therefore not rule out the possibility of some kind of competition between cattle and buffalo in our study area.

Although the intensity of overlap was relatively low in the dry season, especially in June and July, variable habitat overlap occurred between cattle and buffalo. The low intensity of overlap can be attributed to the fact that cattle spent less time in the conservation area in June and July due to having access to agricultural fields that offer crop residues during this time. Joint space use between cattle and buffalo in May and July occurred mainly in Combretum woodland. This result is consistent with Ryan et al. (2006) who reported preference for Combretum woodland by buffalo in similar landscapes. The high overlap within Combretum woodlands can also be explained by the fact that overlaps occurred within eutric fluvisols which are known for retaining soil moisture that allow vegetation to remain photosynthetically active for longer. Common grass species that are favored by both cattle and buffalo such as Digitaria eriantha are also common within Combretum woodlands in the study site. High overlap also occurred in May and June within Mopane woodland which is a preferred dry season habitat by cattle (Zengeya et al., 2014). Kelly and Walker (1976) suggested that the preference of Mopane woodlands by herbivores during the dry season was due to the nutritious senescent/dry leaves. Overlaps also occurred in the dry river bed during the month of May. Spatial overlap was relatively low within riparian woodlands during the dry season contrary to expectation given that these areas provide greener grass and highly nutritious grass species. A plausible explanation is the location of the riparian woodlands in relation to the conservation boundary. Cattle were found to advance more into the conservation area while buffalo rarely approached the edge of the conservation boundary thus affecting the degree of overlap. Habitat overlap in conjunction with diet overlap is one of the prerequisites of the existence of competition (Prins, 2000). Although we did not measure diet overlap, habitat overlap gives stronger support for potential competition when used alone and acts as a preamble to analyzing habitat selection and diet overlap.

Overall, our study demonstrated the existence of resource gradients that correlate with livestock movement into wildlife areas. However, we only provided prerequisites for the existence of competition in a natural setting by focusing on habitat overlap. The study demonstrated the utility of GPS data coupled with remotely sensed data and spatial point pattern statistics in elucidating drivers of spatial overlap between herbivores and quantifying spatial overlap in a spatially explicit manner. To our knowledge this is the first time that simultaneously collected GPS collar data from sympatric species has been used to detect potential competition between the species in Southern Africa. The approach used in this study allowed the detection of interesting spatial associations that occur during the early dry season which may have not been possible using aerial survey data which is often confined to late dry season i.e. in the study site. Resource overlap which is a function of diet and habitat overlap has been regarded as a more direct measure of overlap (Prins, 2000). In this regard, there is need to test similarities in diet overlap between sympatric buffalo and cattle throughout the dry season.

Understanding determinants of movement is key in generating knowledge on spatial and temporal dimensions of species interactions. Thus specific areas that act as hotspots of interaction can be identified allowing opportunities for manipulating access to key resources (water or forage) to reduce contact. Results of this study confirm that conservation areas act as buffer zones for provision of extra forage for livestock although this increases the risk of disease transmission. The challenging question is whether conservation areas should establish buffer zones that can be utilized by livestock only and the other areas are fenced off and maintained. Besides identifying the determinants of habitat overlap there is also need for continued research on the intensity of habitat overlap and its link with disease transmission. This will require extensive monitoring of movement at the interface and thereafter allow development of strategies that reduce the frequency of livestockwildlife spatial and resource overlaps within the GLTFCA.

\section{Acknowledgments}

We are grateful to the Malipati farmers and the Department of Veterinary Service and National Parks Authority for facilitating this study. This work was also conducted within the framework of the Research Platform 'Production and Conservation in Partnership', RP-PCP (RPPCP grant/project CC2). We also thank the University of Zimbabwe for financial support. The project was also supported by the DAAD Zimbabwe In-Country scholarship.

\section{References}

Augustine, DJ. Veblen, KE, Goheen, JR, Riginos, C, Young T.P, 2011. Pathways for positive cattle-wildlife interactions in semiarid rangelands. In: Georgiadis, N.J. (Ed.) Conserving Wildlife in African Landscapes: Kenya's Ewaso ecosystem. Smithsonian Contributions to Zoology, vol. 632. Smithsonian Institution Scholarly Press, Washington, D.C, pp. 55-71.

Bailey, T.C., Gatrell, A.C., 1995. Interactive Spatial Data Analysis. Longman Group Limited, Harlow.

Bennett, J., Lent, P., Harris, P., 2007. Dry season foraging preferences of cattle and sheep in a communal area of South Africa. Afr. J. Range Forage Sci. 24 (3), 109-121.

Berger, J., 2004. The last mile: how to sustain long-distance migration in mammals. Conserv. Biol. 18, 320-331.

Boone, R.B., Thirgood, S.J., Hopcraft, J.G.C., 2006. Serengeti wildebeest migratory patterns modeled from rainfall and new vegetation growth. Ecology 87 (8), 1987-1994.

Börger, L., Francon, N., De Michele, G., Gantz, A., Meschi, F., 2006. Effects of sampling regime on the mean and variance of home range size estimates. J. Anim. Ecol. 75, 1393-1405.

Burroughs, R., Morkel, P., Kock, M.D., Meltzer, D., Hofmeyer, M., 2006 Chemical immobilization-individual species requirements. In: Kock, M.D., Meltzer, D., Burroughs, R. (Eds.), Chemical and Physical Restraint of Wild Animals-A Training Field Manual for African Species, IWVS, Greyton, South Africa, pp. 116-211.

Chenje, M., Sola, L., Paleczny, D., 1998. The State of Zimbabwe's Environment 1998. Government of the Republic of Zimbabwe Ministry of Mines, Environment and Tourism, Harare.

Condit, R., Ashton, P.S., Baker, P., Bunyavejchewin, S., Gunatilleke, S. Gunatilleke, N., Hubbell, S.P., Foster, R.B., Itoh, A., LaFrankie, J.V., Lee, H.S., Losos, E., Manokaran, N., Sukumar, R., Yamakura, T., 2000. Spatial patterns in the distribution of tropical tree species. Science 288, 1414-1418. 
de Garine-Wichatitksy, M., Fritz, H., Chaminuka, P., Caron, A., Pfukenyi, D., Matema, C., Jori, F., Murwira, A., 2013. Consequences of animals crossing the edges of transfrontier parks. In: Andersson, J.A., de Garine-Wichatitsky, M., Dzingirai, V., Giller, K.E., David, C. (Eds.), Transfrontier Conservation Areas: People Living on the Edge, Earthscan, London, pp. 137-162.

Dunham, K.M., van der Westhuizen, E., van der Westhuizen, H.F., Gandiwa, E., 2010. Aerial Survey of Elephants and Other Large Herbivores in Gonarezhou National Park (Zimbabwe), Zinave National Parks (Mozambique) and Surrounds: 2009. Frankfurt Zoological Society, Chiredzi, Zimbabwe.

ESRI, 2005. ArcGIS GIS 9.2. Environmental Systems Research Institute, Redlands, CA.

Fieberg, J., Kochanny, C.O., 2005. Quantifying home-range overlap: the importance of the utilization distribution. J. Wildl. Manag. 69 (4), 1346-1359.

Floyd, M.L., Clifford, M., Cobb, N.S., Hanna, D., Delph, R., Ford, P., Turner, D., 2009. Relationship of stand characteristics to drought-Induced mortality in three Southwestern Piñon-Juniper woodlands. Ecol. Appl. 19 (5), 1223-1230.

Fritz, H., de Garine-Wichatitsky, M., Georges, L., 1996. Habitat use by sympatric wild and domestic herbivores in an African savanna woodland: the influence of cattle spatial behaviour. J. Appl. Ecol. 33 (3), 589-598.

Hebblewhite, M., Merrill, E.,2008, Modelling wildlife-human relationships for social species with mixed-effects resource selection models. J. Appl. Ecol. 45, 834-844.

Hibert, F., Calenge, C., Fritz, H., Maillard, D., Bouché, P., Ipavec, A., Convers, A., Ombredane, D., de Visscher, M.N., 2010. Spatial avoidance of invading pastoral cattle by wild ungulates: insights from using point process statistics. Biodivers. Conserv. 19, 2003-2024.

Huete, A., Didan, K., Miura, T., Rodriguez, E.P., Gao, X., Ferreira, L.G., 2002. Overview of the radiometric and biophysical performance of the MODIS vegetation indices. Remote Sens. Environ. 83, 195-213.

Huete, A., Didan, K., van Leeuwen, W., Miura, T., Glenn, E., 2010. MODIS vegetation indices. In: Ramachandran, B., Justice, C.O., Abrams, M.J. (Eds.), Land Remote Sensing and Global Environmental Change: NASA's Earth Observing System and the Science of ASTER and MODIS, Springer, New York, pp. 579-598.

ITC, 2005. Integrated Land and Water Resources Information System (ILWIS). International Institute for Geo-information Science and Earth Observation, Enschede.

ITT Visual Information Solutions, 2009. ENVI 4.9. ITT Industries Inc., Colorado.

Jarman, P.J., Sinclair, A.R.E., 1979. Feeding strategy and the pattern of resource partitioning in ungulates. In: Sinclair, A.R.E., NortonGriffiths, M. (Eds.), Serengeti: Dynamics of an Ecosystem, University of Chicago Press, Chicago, Illinois, USA, pp. 130-163.

Kelly, D., Walker, B.H., 1976. The effects of different forms of land use on the ecology of a semi-arid area in southeastern Rhodesia. J. Ecol. 64, $553-576$.

Lagrange, M., 2006. Overview of capture methods and transport of wild animals. In: Kock, M.D., Meltzer, D., Burroughs, R. (Eds.), Chemical and Physical Restraint of Wild Animals-A Training Field Manual for African Species, IWVS, Greyton, South Africa, pp. 250-259.

Lamarque, F., Anderson, J., Fergusson, R., Lagrange, M., Osei-Owusu, Y. Bakker, L., 2009. Human-wildlife conflict in Africa: causes, consequences and management strategies. Food and Agriculture Organization of the United Nations (FAO). FAO Forestry paper, vol. 157, Rome, Italy, pp. vii +98 .

Loarie, S.R., van Aarde, R.J., Pimm, S.L., 2009. Elephant seasonal vegetation preferences across dry and wet savannas. Biol. Conserv. 142 (2009), 3099-3107.

Loft, E.R., Menke, J.W., Kie, J.G., 1991. Habitat shifts by mule deer: the influence of cattle grazing. J. Wildl. Manag. 55 (1), 16-26.

Macandza, V.A., Owen-Smith, N., Cross, P.C., 2004. Forage selection by African buffalo in the late dry season in two landscapes. S. Afr. J. Wildl, Res. 34, 113-121.

Madhusudan, M.D., 2004. Recovery of wild large herbivores following livestock decline in a tropical Indian wildlife reserve. J. Appl. Ecol. 41, 858-869.

McLoughlin, P.D., Ferguson, S.H., 2000. A hierarchical pattern of limiting factors helps explain variation in home range size. Ecoscience 7 (2), $123-130$.
Murwira, A., de Garine-Wichatitsky, M., Zengeya, F., Poshiwa, X., Matema, S., Caron, A., Guerbois, C., Hellard, E., Fritz, H., 2013. Resource gradients and movements across the edge of transfrontier parks. In: Andersson, J.A., de Garine-Wichatitsky, M., Cumming, D.H.M., Dzingirai, V., Giller, K.E. (Eds.), Transfrontier Conservation Areas: People Living on the Edge, Earthscan, London, pp. 123-136.

Naidoo, R., Du Preez, P., Stuart-Hill, G., Weaver, C.L., Jago, M., Wegmann, M., 2012. Factors affecting intraspecific variation in home range size of a large African herbivore. Landsc. Ecol. 27, 1523-1534.

Nyamudeza, P., Hussein, J., Matibiri, B., 2001. The sustainable management of vertisols. In: Syers, J.K., Penning De Vries, F.W.T., Nyamudeza, P. (Eds.), Vertisols Management in Zimbabwe, CABI International, Wallingford, pp. 139-140.

Odadi, W.O., Karachi, M., Abdulrazk, S., Young, T.P., 2011. African wild ungulates compete with or facilitate cattle depending on season. Science 333, 1753-1755.

Perry, G.L., Miller, B.P., Enright, N.J., 2006. A comparison of methods for the statistical analysis of spatial point patterns in plant ecology. Plant Ecol. 187, 59-82.

Prins, H.H.T., 1996. Ecology and Behaviour of the African Buffalo: Social Inequality and Decision Making. Chapman and Hall, London, UK.

Prins, H.H.T., 2000. Competition between wildlife and livestock in Africa. In: Prins, H.H.T., Grootenhuis, J.J., Dolan, T.T. (Eds.), Wildlife Conservation by Sustainable Use. Conservation Biology Series, vol. 12. Kluwer Academic Publishers, Boston, pp. 51-80.

Prins, H.T.T., Olff, H., 1998. Species richness of African grazer assemblages: towards a functional explanation. In: Newberry, D.M., Brown, N., Prins, H.T.T. (Eds.), Dynamics in Tropical Communities, Blackwell, Oxford, pp. 449-490.

Redfern, J.V., Grant, R., Biggs, H., Getz, W.M., 2003. Surface-water constraints on herbivore foraging in the Kruger National Park, South Africa. Ecology 84, 2092-2107.

Roerink, G.J., Menenti, M., Verhoef, W., 2000. Reconstructing cloudfree NDVI composites using Fourier analysis of time series. Int. J. Remote Sens. 21 (9), 1911-1917.

Ryan, S.J., Knechtel, C.U., Getz, W.M., 2006. Range and Habitat Selection of African Buffalo in South Africa. J. Wildl. Manag. 70 (3), 764-776.

Seaman, D.E., Powell, R.A., 1996. An evaluation of the accuracy of kernel density estimators for home range analysis. Ecology 77, 2075-2085.

Sinclair, A.R.E., 1985. Does interspecific competition or predation shape the African ungulate community? J. Anim. Ecol. 54, 899-918.

Stewart, K.M., Bowyer, R.T., Kie, J.G., Cimon, N.J., Johnson, B.K., O'Shea, T.J., 2002. Temporospatial distributions of elk, mule deer, and cattle: resource partitioning and competitive displacement. J. Mammal. 83, 229-244.

Vavra, M., Willis, M.J., Sheehy, D.P., 1999. Livestock-big game relationships: conflicts and compatabilities. In: Launchbaugh, K.L., Sanders, K. D., Mosley, J.C. (Eds.), Grazing Behaviour of Livestock and Wildlife, University of Idaho, Moscow, pp. 130-133.

Voeten, M.M., Prins, H.T.T., 1999. Resource partitioning between sympatric wild and domestic herbivores in the Tarangire region of Tanzania. Oecologia 120, 287-294.

Winnie, J.A., Cross, P., Getz, W., 2008. Habitat quality and heterogeneity influence distribution and behavior in African Buffalo (Syncerus caffer). Ecology 89 (5), 1457-1468.

Worton, B.J., 1989. Kernel methods for estimating the utilization distribution in home-range studies. Ecology 70, 164-168.

Xiao, X., Zhang, Q., Braswell, B., Urbanski, S., Boles, S., Wofsy, S., Moore, B., Ojima, D., 2004. Modeling gross primary production of temperate deciduous broadleaf forest using satellite images and climate data. Remote Sens. Environ. 91, 256-270.

Zengeya, F., Murwira, A., de Garine-Wichatitksy, M., 2014. Seasonal habitat selection and space use by a semi-free range herbivore in a heterogeneous savanna landscape. Aust. Ecol.

Zengeya, F., Murwira, A., de Garine-Wichatitsky, M., 2011. An IKONOS based comparison of methods to estimate cattle home ranges in a semi-arid landscape of southern Africa. Int. J. Remote Sens. 32, 7805-7826.

Zengeya, F., Mutanga, O., Murwira, A., 2013. Linking remotely sensed forage quality estimates from WorldView-2 multispectral data with cattle distribution in a savanna landscape. Int. J. Appl. Earth Obs. Geoinf. 21, 513-524. 